\title{
O PÚBLICO COMO UM DISPOSITIVO NO CAMPO DA SAÚDE PÚBLICA
}

\author{
The public as a device in the \\ field of public health
}

\author{
Anita Guazzelli Bernardes ${ }^{\text {a }}$ Eduardo Cavalheiro Pelliccioli ${ }^{\mathrm{b}}$ \\ a Universidade Católica Dom Bosco, Doutora em Psicologia pela Pontifícia Universidade Católica do Rio Grande do Sul, Porto \\ Alegre, RS - Brasil, e-mail: anitabernardes@ig.com.br

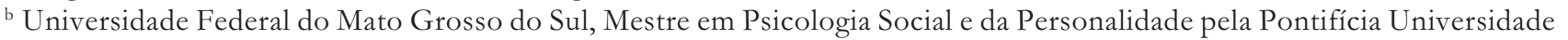 \\ Católica do Rio Grande do Sul, Porto Alegre, RS - Brasil, e-mail: edupelliccioli@yahoo.com.br
}

\begin{abstract}
Resumo
Este artigo problematiza o público como um dispositivo na constituição do campo da saúde pública no Brasil. Trata-se de uma genealogia do público no que tange aos modos como este se aproxima do campo da saúde e as formas de subjetivação produzidas nessa articulação. Essa forma de aproximação do público com a saúde, neste estudo, focaliza os investimentos políticos nas figuras do trabalhador/ operário e na familia. Para a construção dessa discussão, serão utilizadas algumas linhas histórico-políticas referentes à saúde pública no Brasil, bem como as ferramentas conceituais foucaultianas sobre poder, verdade e subjetividade. Tais estratégias subsidiam a compreensão do campo da saúde pública como um território do outro, um outro desfiliado do privado, um outro que expressa o modo de existência de certa formação histórica que publiciza aquilo que lhe escapa.
\end{abstract}

Palavras-chave: Público; Dispositivo; Formas de subjetivação; Saúde pública. 


\begin{abstract}
This article problematizes the public as a device in the constitution of the field of public health in Brazil. It has to do with a genealogy of the public regarding the ways through which the latter approximates to the health field and the forms of subjectivation produced in this articulation. This form of approximation between public and health, in this study, has been focused on the political investments in the figures of both the worker/laborer and the family. In order to construct this discussion, some historical, political lines related to public health in Brazil have been used, as well as Foucauldian conceptual tools about power, truth, and subjectivity. Such strategies have subsidized the understanding of the public health field as a territory of the other, the other that is disaffiliated from the private, the other that expresses the way of existence of a certain historical formation which publicizes what escapes from it.
\end{abstract}

Keywords: Public; Device; Forms of subjectivation; Public health.

\section{INTRODUÇÃO}

Este artigo problematiza o público como um dispositivo na constituição do campo da saúde pública no Brasil. É uma análise que objetiva uma genealogia do público no que tange aos modos como este se aproxima do campo da saúde e as formas de subjetivação produzidas nessa articulação. Essa maneira de aproximação do público com a saúde, neste estudo, focaliza os investimentos políticos nas figuras do trabalhador/operário e na família. O que interessa para esta discussão é o lugar que o público assume para a saúde e, ao articular-se a esta, como constitui certas estratégias e figuras existenciais, tanto no que diz respeito aos modelos de assistência à saúde quanto no que se refere aos sujeitos foco desses investimentos: trabalhador e família.

A emergência desse campo encontra suas condições de possibilidade na formulação do público como um dispositivo da modernidade, um dispositivo de publicização que dá visibilidade à saúde e à vida. Segundo as considerações de Foucault (1999) sobre esse conceito, um dispositivo que engendra um campo de lutas entre público e privado, conformando especificidades desses territórios não mais como a experiência greco-romana relativa ao mercado de trocas e ao lar/família, mas relacionada à propriedade, seja esta de si mesmo, do Estado ou dos meios de produção.

Utilizar o conceito de dispositivo é percorrer uma lógica que constrói e medeia a relação do sujeito consigo mesmo, produzindo certos modos de experimentar a si mesmo e de relacionar-se com o outro, uma ontologia do presente em que o humano se fabrica no interior de certos aparatos. A operação que o conceito de dispositivo oferece ao pensamento é tanto no sentido da forma como iremos nos interrogar acerca da conformação de um modo de publicização na saúde, quanto no dos objetos tomados por essa articulação, ou seja, é o próprio dispositivo que nos permite objetivar essas formas.

Um dispositivo não apenas anexa um objeto a um campo de racionalidade, fazendo-o um objeto-história, um objeto-significação, um objetodiscurso, mas, sobretudo, faz dessa objetivação um modo de subjetivação, torna-se corpo, torna-se alma, torna-se uma interioridade. Não se trata de perscrutar a representação do público, e sim um processo de produção de agenciamentos que, ao articular distintos objetos, constitui territórios existenciais. Desse modo, utilizar o conceito de dispositivo não se traduz na busca de um território epistemológico do público, mas das percepções, práticas, saberes que engendram o público como uma estratégia do campo da saúde que ganha um estatuto de legitimidade na medida em que passa a fazer parte de um dispositivo. É pensar na rede que se tece entre o público e as práticas sociais que lhe dão condições de visibilidade e dizibilidade como um território de produção de sujeitos no campo da saúde.

Para a construção da discussão, serão utilizadas algumas linhas histórico-políticas referentes à saúde pública no Brasil. Trata-se de linhas histórico-políticas no sentido de estratégias de poder que são colocadas em jogo: heranças 
européias, trabalho, identidade nacional, industrialização e família. Tais estratégias subsidiam a compreensão do campo da saúde pública no Brasil como um território do outro, um outro desfiliado do privado, um outro que expressa o modo de existência de certa formação histórica que publiciza aquilo que lhe escapa. Marca-se, com isso, a função de controle do outro para o progresso da "nação brasileira".

\section{HERANÇAS EUROPÉIAS PARA A CONSTITUIÇÃO DE UM DISPOSITIVỎ DE UBLICIZAÇÃO DO BRASIL}

Segundo Foucault (1995), a urbanização, recrudescida com a revolução industrial na Europa nos séculos VI, VII e VIII, desenvolve o campo de intervenção da medicina social. A teia de relações entre o nascimento da medicina social e da microbiologia, a urbanização e o desenvolvimento do Estado é condição de emergência do público como população que deve ser disciplinada por meio de biopolíticas. As relações de força e forma recaem e dão visibilidade aos corpos da população, aos seus hábitos, esquadrinhando e organizando o espaço social de modo a evitar os contatos que contaminam. O desenvolvimento de centros urbanos alavanca, concomitantemente, a produção. Ocorre uma transformação do público, antes tido como lugar de trocas e mercado (Arendt, 1989), e agora como espaço de produção: industrial, populacional, epidemiológica, urbanizacional. Essas aglomerações geram, não espontaneamente, o medo, uma "inquietude político-sanitária que se forma à medida que se desenvolve o tecido urbano" (Foucault, 1995a, p. 87). Emergem, então, tecnologias de controle dos nascimentos, dos óbitos, das habitações, enfim, dos modos de viver.

A medicina social incorpora-se ao tecido urbano e passa a fazer parte dos modos de organização social; ela inscreve e demarca, por meio de estratégias de controle, a divisão entre ricos e pobres. Esse esquadrinhamento ocorre tanto no que diz respeito ao modelo de assistência médica quanto no que se refere à localização no espaço. Essas duas características - assistência médica e localização no espaço -, quando relacionadas à saúde na formação dos espaços urbanos e da industrialização, engendram a sobreposição de uma política disciplinar e de uma política sobre a vida. A discussão que Foucault (1999) faz sobre o biopoder conflui essas duas formas de o poder exercer-se: anátomo-política e biopolítica. Ao controle do corpo espacializado, agrega-se o controle da vida. O corpo individual acomoda-se no corpo da população. O biológico justapõe-se ao político, torna-se um instrumento, torna-se uma técnica política. Quando a medicina social passa a regular o espaço urbano e os modos de viver da população pobre, o controle sobre as epidemias torna-se possível. Esse controle sobre as epidemias e os modos de viver faz da vida um objeto de saber e intervenção.

As estratégias de biopoder formuladas pela agregação entre Estado moderno, medicina social, industrialização e pauperização territorializam a população e a vida como objeto por meio da assistência à saúde. As políticas engendradas nessa articulação compõem um território sociológico quando situam a população e a vida como focos de investimentos do Estado. Esse processo torna possível conformar uma experiência de público que correlaciona campos de saber, como a "razão de Estado", a população, a vida, a pauperização e a industrialização, com tipos de normatividade, como a disciplina e a biopolítica, e com formas de subjetivação, tais como o pobre epidêmico e revoltado, o trabalhador/operário.

Essa experiência de público, constituída na racionalidade moderna, tem suas condições de possibilidade na periculosidade que a pauperização apresenta para o progresso e o desenvolvimento social. Torna-se uma questão que deve ser capturada pelo Estado e investida. A política que aparece como estratégia é o controle das populações por meio da saúde, da salubridade e insalubridade do corpo social uma política médico/policial. Desse modo, a emergência do público é possível justamente pela emergência da vida e da saúde como objetos de saber e intervenção. Mas são esses regimes de verdade em relação à saúde, especificamente à saúde da população, que conformam o público como uma experiência relativa à pobreza, à epidemia e a conflitos sociais.

A saúde torna-se uma urgência a ser respondida, e a resposta a essa urgência atualizase na figura do Estado. A saúde torna-se um caso, torna-se uma problemática. Mas não se trata de qualquer saúde - trata-se da saúde da população 
pobre, a saúde do pauperismo. A urgência não é com a saúde como fato, mas a saúde como ameaça ao progresso. O público torna-se um campo de lutas em que se atravessam a medicina social, a polícia e a figura jurídica do Estado, bem como os movimentos de resistência, tais como a organização operária e os conflitos urbanos originados pela fome e miséria. Isso implica a criação de um campo de visibilidade e dizibilidade, bem como de controle e produção de subjetividades - um dispositivo de publicização, um dispositivo que tem a saúde como objeto imprescindível de articulação e ação.

Isso implica um tropos na constituição do público que, num primeiro momento, é relativo ao mercado de trocas, ao homo faber, ao lugar onde o humano se dá a conhecer na experiência grecoromana e passa a constituir um território referente ao Estado de proteção, de seguridade de uma população precarizada nas formas de viver devido ao pauperismo e às epidemias engendrados pela industrialização. A emergência do dispositivo de publicização ampara-se nessa "questão social" (Castel, 1998), de modo a transformar a experiência do público como território psicológico de constituição de indivíduos em território sociológico de constituição de massas, grupos e comunidades.

Nesse caso, o dispositivo de publicização não deve ser procurado, unicamente, em uma instância central, como o Estado, por exemplo, pois o dispositivo não é uma estrutura, não é certa potência da qual o Estado seria dotado: o dispositivo é uma situação estratégica complexa, é uma rede, um tipo de jogo. E preciso procurar o dispositivo capilarmente, nas relações que se estabelecem entre um ponto e outro. O dispositivo de publicização torna-se um dispositivo não por se referir a um único domínio, o do Estado, mas porque se estende pelo tecido social e cria a própria tecitura desse tecido. Isso porque, ao tornarse um domínio do Estado, o público é instituído como um objeto possível e, sendo possível de objetivação, torna-se foco de investimentos mediante tecnologias de governo de si e do outro e procedimentos discursivos. $\mathrm{O}$ dispositivo não se faz presente pelo fato de tornar tudo uma unidade intransponível, mas porque se produz a cada instante, com estratégias que o tornam cada vez mais necessário, indispensável.

\section{O PÚBLICO ENCONTRA-SE COM O TRABALHO}

A publicização é a possibilidade de articulação da saúde com a população como uma problemática do campo político frente à objetivação do indivíduo perigoso ou da classe perigosa "os inimigos que se trata de suprimir não são os adversários no sentido político do termo; são os perigos, externos ou internos, em relação à população e para a população" (Foucault, 2005, p. 306). O processo de federalização do país acaba por criar fissuras no próprio tecido social. Essas fissuras são produzidas pelos grupos que a Constituição de 1891 não incluiu: a urbanização e a entrada do operário industrial por meio da imigração. A oligarquia começa a defrontar-se com algo que não fazia parte daquilo que havia sido delimitado como nação brasileira: o operário. Por meio de greves que eclodem a partir de 1917, o operário passa a apresentar-se como uma classe perigosa, como um perigo interno no seio da própria população (Pinto, 1999).

O aparecimento do operariado no Brasil torna-se uma "questão social" em virtude não somente das greves, como também da sindicalização e da partidarização ${ }^{1}$. Esse movimento, entre outros, começa a modificar o que aparecerá na Constituição de 1934. A Constituição, segundo Pinto (1999), é a primeira a objetivar a população brasileira. E a Constituição onde se encontra uma arte de governar por meio da relação constitucional que se estabelece entre Estado e o conjunto da população:

A Constituição de 1934 é a primeira em que é nomeado o povo, a população e os brasileiros, em oposição aos estrangeiros: pela primeira vez o país é nomeado como composto de um conjunto de pessoas, organizadas em famílias, por sexos diferentes, em estágios geracionais diversos, com diferentes graus de riqueza, com direitos específicos e particulares e, mais importante do que tudo isto, uma população de trabalhadores, com direitos assegurados (Pinto, 1999, p. 44).

Esses trabalhadores com direitos assegurados passam a ser objetivados por duas instâncias administrativas: Ministério da Educação e Saúde

\footnotetext{
O Partido Comunista é fundado em 1922 por operários e simpatizantes.
} 
Pública e o Ministério do Trabalho. O nó de articulação entre essas instâncias é feito pela cotização salarial. O trabalho passa a ser um marcador de acesso a suportes em saúde. A saúde passa a ser composta como um eixo da educação e possível pela legislação trabalhista.

A emergência dos Ministérios da Educação e Saúde Pública e do Trabalho começa a delinear uma outra forma de o poder exercer-se. Ao poder disciplinar, começa a integrar-se um poder regulamentar. O aparecimento da população nas Constituições do Brasil implica transformar os modos de governo, ou seja, um Estado de governo definido não mais pelo território, mas pela massa que habita esse território. O território deixa de ser uma expressão geográfica e passa a ser uma manifestação sociológica. Cria-se a necessidade de a economia política voltar-se para a população: "a massa da população, com seu volume, sua densidade, com, certamente, o território sobre o qual ela se estende, mas que não é dela senão um componente" (Foucault, 2003, p. 305). Desse modo, a população passa a ser um componente da Nação, um componente que deve ser regulamentado, controlado, pois é justamente a população que escapa a determinadas formas de dominação.

O que escapa, essas formas de resistência, como o movimento operário, não foi sempre o objetivo final de todo o assujeitamento, pois a população passa a ter visibilidade justamente quando as estratégias disciplinares não são mais suficientes para manter sua opacidade. As estratégias de segurança/policiais precisam articular-se a outras ações, precisam integrar a população como um problema político, como um problema de governo. As tecnologias disciplinares agregam-se às tecnologias previdenciárias/ regulamentadoras. Desse modo, o disciplinar unese ao regulamentar, na medida em que o controle dos comportamentos e ações passa a ser normatizado em termos de legislação.

Esse acoplamento do Estado às formas de viver conforma um conjunto com regras próprias de funcionamento, engendra uma bio-regulamentação. São regulamentações que agem nos comportamentos, no modo como a população deve viver: caixas de aposentadorias que asseguram a saúde e a velhice, higiene das famílias como forma de preservação e reprodução da vida, escolaridade. No que tange às políticas de saúde, a regulamentação age em termos de profilaxia rural e urbana, criação de dispensários, recenseamento de doenças infecto-contagiosas, criação de preventório para recolhimento dos filhos sadios de portadores de doença. A concepção de polícia sanitária e de eugenia dominava as ações, e o termo "vigilância sanitária" era usado para o controle sanitário de estabelecimentos, locais e pessoas doentes ou suspeitas de doenças transmissíveis. A racionalidade que se engendra sustenta-se no fazer viver ou no deixar morrer. E o fazer viver vai encontrar no trabalho uma das possibilidades de sua articulação.

O trabalho assalariado torna-se um foco do dispositivo de publicização. É preciso tornálo um domínio, é preciso regulamentá-lo. Isso porque o trabalho é a via pela qual se institui a regulamentação, bem como a via por onde se escapa à regulamentação. Essa porosidade do trabalho cria a necessidade de controlá-lo em termos de massa de resistência, mais do que propriamente otimização da força de trabalho. O investimento nessa figura emergente do operário/ trabalhador é uma questão de seguridade para o Estado tanto em relação às reservas e acumulação quanto à possibilidade de governamentalidade.

O dispositivo de publicização aparece, dessa forma, como norma que passa a circular entre população/Estado, população/urbano. As bases dessa norma encontram-se na cientificização da vida cotidiana. Tal cientificização diz respeito a uma economia política. É preciso publicizar o cotidiano para governar; a vida tem que sair do âmbito da economia doméstica para o âmbito da economia política. $\mathrm{O}$ dispositivo de publicização faz viver ou deixa morrer. O fazer viver ou deixar morrer em termos de economia política engendra uma cesura no tecido social: doenças e ausência de doenças, assalariados e não-assalariados, crianças e adultos, homens e mulheres, graus de riqueza. Esse exercício cria no interior da população uma série de agrupamentos que são marcados pela norma. A normalização direciona as estratégias políticas em termos biológicos, uma tecnologia que "vai deixar a vida em geral mais sadia; mais sadia e mais pura" (Foucault, 2005, p. 305): profilaxias, recenseamentos, dispensários, preventórios.

Entretanto, é importante marcar que a "questão social" que emerge na primeira república e na república de Vargas refere-se ao campo do 
trabalho e das afecções do corpo da população. A "questão social" não diz respeito à miserabilidade e precariedade da vida no espaço urbano e rural. A publicização ilumina o trabalho e as doenças, e não especificamente a pobreza - a esta, cabe deixar morrer, de acordo com os ideais higienistas e eugenistas. O tornar a "vida sadia" recai sobre as condições de trabalho e as condições sanitárias do espaço urbano e rural em virtude de uma economia de caráter exportador.

A lógica de investimento em determinados focos e não em outros, por exemplo, no trabalho/doença, e não na pobreza, formula-se na racionalidade moderna de produção de refugo social. O refugo é efeito do próprio processo de lapidação e desenvolvimento social: "a separação e destruição do refugo seriam o segredo comercial da criação moderna" (Bauman, 2005). A produção de "lixo social" é indispensável para o crescimento da nação, portanto, deixa-se morrer o supérfluo, o desnecessário.

As biopolíticas que começam a se entrepor no tecido social apresentam um plano de bifurcação: por um lado, é necessário filiar, amarrar; por outro, é preciso fragmentar, separar. A filiação dá-se em termos de regulamentos que atribuem ao Estado certas responsabilidades, por exemplo, participação nos financiamentos e administração de suportes sociais ao trabalhador. Por outro lado, ao responsabilizar-se pela vigilância sanitária, subdivide e fragmenta a população a partir de codificações científicas: higienismo, profilaxia e degenerescência. A saúde pública não é em si mesma um eixo de responsabilidade do Estado. A saúde é uma derivada das possibilidades de governo do Estado, portanto, acoplada à Educação, aos Negócios e ao Trabalho.

A atribuição ao Estado da responsabilidade de tornar a "vida mais sadia" por meio da regulamentação do trabalho e do espaço urbano e rural aproxima a saúde da população. Mas, para gerir essa relação, são necessárias condições de possibilidade. Essas condições são articuladas mediante a publicização da vida. Tal publicização encontra no racismo uma de suas principais inscrições, quer dizer, o fazer viver ou o deixar morrer é assegurado ao Estado pelo racismo. A função do racismo de Estado surge como uma tecnologia de publicização, tecnologia essa que vai marcar a própria experiência do público. $\mathrm{O}$ racismo de Estado faz uma cesura no tecido social ao marcar aqueles grupos dos quais o Estado deve ser parceiro (oligarquias) e os grupos que o Estado deve assistir - trabalhador, família, jovens, crianças. A assistência do Estado, o amparo do Estado, regulamenta-se a partir da necessidade de apropriarse da complexidade da população para equilíbrio nacional assentado em uma lógica de estado de direito. Esse investimento do Estado une medicina e higiene social. A experiência do público formulase nessa instância de articulação entre as práticas de regulamentação da vida cotidiana por meio de normas trabalhistas e sanitaristas, de produção de verdades sobre a relação entre contágio e afecções, bem como de formas de subjetivação pelo trabalho: a figura do operário.

Como se trata de um jogo, o dispositivo de publicização opera segundo uma racionalidade centralizadora, o que justamente lhe permite o engendramento de um território público, uma experiência de público. As biopolíticas que constituem uma territorialização do público encontram na "crescente tendência intervencionista da União" (Serres, 2003, p. 86) seu ponto de apoio ao articulá-la a um racismo de Estado. A criação do Ministério da Educação e Saúde Pública objetivava romper com os regionalismos a partir da visibilidade que se dá às condições sanitárias: "interdependência entre as unidades federativas e as limitações das soluções localizadas" (Serres, 2003, p. 86). O racismo de Estado e o projeto de centralização e uniformização dos serviços sanitários apresentam-se como tecnologias de expansão do Estado Nacional. "A saúde, nesse período, foi alçada a importante sustentáculo na constituição da identidade nacional. O Estado conseguiu forças para atuar em todo o território, sobrepondo-se a interesses e autonomias regionais através da extensão do aparato governamental" (Serres, 2003, p. 89). A expansão do Estado Nacional coloca na agenda os problemas sanitários: organização sanitária, combate às grandes endemias e identidade nacional.

\section{SAÚDE E IDENTIDADE NACIONAL}

Esses três eixos de produção organização sanitária, combate às grandes endemias e identidade nacional -, amarrados ao trabalho, referem-se a uma nova configuração do público. A configuração do público, então, 
apresenta-se como condições segundo as quais se atualiza um conjunto de práticas que requerem intervenções específicas e produzem um novo arranjo social. Esse novo arranjo social - a constituição de uma identidade nacional - coloca na agenda do público a objetivação do trabalhador e da saúde. A objetivação desse modo de subjetivação - identidade nacional - encontrará um ponto de apoio importante na objetivação da família. A família, o trabalhador e a saúde são colocados sob a responsabilidade do Estado, marcando de forma mais efetiva tanto a noção de população quanto a de biopolítica.

O Estado publiciza a economia doméstica e cria, como sua atribuição, a responsabilidade do "futuro" do mundo público - "cumprimento dos deveres para com a economia" (Pinto, 1999, p. 45). O trabalhador e a família são publicizados em termos de direitos (seguridade social) e deveres (disciplina e moral) e passam a ser nomeados e divididos em grupos; a saúde torna-se uma política de governo em "defesa da Nação".

A defesa da Nação atualiza, no projeto de centralização da saúde e no racismo de Estado, um conjunto de práticas, de tecnologias biopolíticas. Tais tecnologias são constituídas pela relação entre medicina e higiene/eugenia, formulando-se um vínculo entre influências científicas e processos biológicos, um vínculo que tem como efeito uma homeostasia populacional (Foucault, 2005). As biopolíticas inserem a centralização e o racismo como tecnologias de governo. A centralização e o racismo formulam uma identidade nacional.

A identidade nacional precisará ser circunscrita por um conjunto de verdades: o trabalhador será objetivado no sentido de legislação trabalhista e de economia doméstica. As tecnologias de controle em termos de organização sanitária e combate a endemias captura o trabalhador por meio da experiência da economia doméstica, por meio de uma experiência do privado. A família passa a ter visibilidade na relação que se estabelece entre ela e o trabalho, entre ela e os meios de produção, entre ela e a identidade nacional. Investir na regulamentação do trabalho é investir na regulamentação da vida doméstica.

Família e trabalhador saem da opacidade do âmbito doméstico para a visibilidade do público: "O Estado se compromete a amparar a maternidade, a infância, a família de prole numerosa, a juventude e, principalmente, os filhos dos operários" (Pinto, 1999, p. 45). Objetivar, em termos de biopolíticas, a família e o trabalhador é territorializar um marcador identitário - a Nação. A nacionalização produz essas formas de subjetivação, que encontram na identidade nacional seu ponto de equilíbrio e a justificativa das ações centralizadoras e racistas.

Com a análise do dispositivo de publicização, aparecem problemas específicos da população, problemática que instala uma série: saúde-trabalho-família. Essa série é pensada em termos de racismo, um racismo que constitui um campo de ações em saúde de forma localizada. A inteligibilidade do racismo conforma-se segundo a noção de saúde como ausência de doença, fundamentando a doença como impedimento ao desenvolvimento individual ou da nação. A racionalidade do racismo ampara-se na relação entre contágio e estrangeiro ${ }^{2}$, entre normal e anormal, entre o eu e o outro, outro que deve se tornar um igual ou ser exterminado.

Mas a essa série também cabe um modo de governo, ou seja, uma inteligibilidade que necessita de uma economia política - a centralização. A centralização dá-se, então, em termos de práticas administrativas - Delegacias Federais de Saúde, Serviços Nacionais de Saúde, Conferências Nacionais de Saúde -, enquanto que as práticas de assistência se dão pela lógica do isolamento: profilaxias urbanas, dispensários, colônias e preventórios, conjuntos habitacionais para operários (cortiços próximos às fábricas). Ou seja, a agenda de saúde pública referese às ações de combate a doenças infecto-contagiosas e à organização sanitária por meio das regulações do trabalho e da família: seguro-saúde, seguro-velhice, localização de habitação, regras de higiene da família, cuidados com as crianças, escolaridade. É preciso separar para administrar.

A identidade nacional é a estratégia de desenvolvimento nacional que encontra na cesura da população sua possibilidade de expressão. A saúde pública não se constitui, desse modo, como um suporte social, mas como uma fragmentação do tecido social e desenvolvimento da identidade nacional. A experiência de publicização da vida cotidiana separa em agrupamentos e centraliza em termos de governo.

\footnotetext{
${ }^{2}$ Estrangeiro como aquilo que não é reconhecido como próprio de uma Nação ou de um sujeito.
} 


\section{INDUSTRIALIZAÇÃO DO PÚBLICO: Saúde e desenvolvimento econômico}

A saúde pública começa a engendrar-se como um objeto, um objeto da economia política, uma maneira de o poder capilarizar-se e exercer-se no interior da economia doméstica. A saúde pública constitui-se de relações políticas que investem na trama de nossa existência (Foucault, 1974) ao tornarse um dever do Estado, mas como um dever de regular a população. $\mathrm{O}$ controle das populações recairá sobre o trabalhador, e sua pacificação, sobre a família e sua responsabilização. O exercício biopolítico engendrado pela questão "quanto melhores as condições de saúde da população, tanto maiores serão as possibilidades econômicas de um país" (Portal, 2005, p. 3) desloca o dever do Estado para o dever do operário, o dever da família. Ou seja, ao objetivarem operário e família como focos das funções administrativas do Estado, as estratégias políticas iluminam essas existências de modo a constituir o sujeito público, ao mesmo tempo em que inscrevem no sujeito público a responsabilidade do desenvolvimento da identidade nacional, entendida também como desenvolvimento econômico da nação. Ambos, operário e família, trabalharão para o desenvolvimento da nação.

O dispositivo de publicização conforma uma experiência de família e de trabalho como condições de possibilidade de acesso aos suportes em saúde: "a assistência sanitária é incorporada à Previdência Social" (Brasil, 2001, p. 289). O dispositivo de publicização torna a saúde um domínio público, operando com o deslocamento de população para família e operários e destes para o sujeito público, o sujeito de deveres. Ser população de uma nação é ter família ou ter trabalho; ser um sujeito público é ter o dever de constituir família e tornar-se um trabalhador. Ter acesso à seguridade cola a família ao trabalho, na medida em que a família se torna segurada pelo trabalhador; a assistência e a previdência são para os trabalhadores e seus familiares.

Aceleram-se a urbanização e a industrialização, que têm como correlato uma política que centraliza as questões sociais em termos de desenvolvimento econômico, e não de políticas sociais. "Vive-se um intenso processo de construção e compra de hospitais, ambulatórios e equipamentos, por parte dos institutos, e de celebração de convênios para prestação de assistência médico-hospitalar aos segurados" (Brasil, 2001, p. 290). Há também a inclusão de outros benefícios aos segurados, como habitação, empréstimos e alimentação. Ou seja, a urbanização e a industrialização ampliam as necessidades de desenvolvimento da população - família e operário -, agregando-se à previdência a assistência, a habitação, os empréstimos e a alimentação.

A incorporação da assistência, da habitação e da alimentação não diz respeito a uma reformulação do conceito de saúde. A saúde ainda é considerada em termos de endemias e epidemias, fato encontrado na proliferação e crescimento de hospitais, ambulatórios e equipamentos médicohospitalares. Assistência, habitação e alimentação são derivadas do movimento dos trabalhadores, e não problematização de políticas sociais.

O dispositivo de publicização possibilita o jogo que coloca a saúde pública como um instrumento para a medicina e o Estado se exercerem sobre a população. A medicina desenvolve-se, o Estado desenvolve-se por meio da publicização do trabalhador e de sua família. A publicização agrega saúde pública ao trabalhador e à família, de modo a encontrarmos duas capilaridades de formas de subjetivação no dispositivo: medicina e Estado como agências públicas, via criação do Ministério da Saúde em 1953, e as atividades médico-sanitárias integradas ao Plano Nacional de Desenvolvimento; trabalhador e família como sujeitos públicos, via seguridade mediante a racionalidade de "saúde de um povo como corolário de seu desenvolvimento econômico" (Brasil, 2001, p. 290).

Mas ocorre que, ao mesmo tempo em que o dispositivo publiciza, uma das operações que faz é privatizar, individualizar. A privatização como uma operação da publicização constitui-se, de um lado, pela industrialização e abertura ao capital estrangeiro/privado, por outro lado, pela localização das afecções morais e físicas em uma região de interioridade-corpo/organismo. Assim, ocorre uma bifurcação na conformação da experiência de publicização: uma coordenada direciona para a luminosidade que o trabalhador $\mathrm{e}$ a família passam a ter por meio da seguridade social; uma outra coordenada localiza essa seguridade em uma zona de privatividade, seja no corpo do trabalhador, seja no interior da família.

Iluminar trabalhador e família torna-se uma estratégia para possibilitar a industrialização do país, na medida em que a saúde passa a ser 
objetivada como "corolário" do desenvolvimento econômico. Desse modo, a saúde torna-se um vetor de publicização da vida cotidiana, definindose a relação entre trabalhador/família e Estado/ medicina por meio da saúde pública. Mas a Saúde Pública não surge como um mediador, tampouco como uma prática de cuidados de si, mas sim como possibilidade de desenvolvimento industrial.

Trata-se de uma publicização da vida que encontra na industrialização sua justificativa e ao mesmo tempo sua finalidade. A saúde pública não se impõe ao trabalhador/família, mas é constitutiva desse trabalhador/família como estratégia para o desenvolvimento urbano e industrial. Aqueles que não estão inscritos como operário ou como família é como se não existissem, são vidas não-vistas, localizadas na clausura; o que se considera como lixo urbano, como aquilo que sobra das categorias de objetivação da população, vai ser colocado ao redor da cidade, margeando o público, embora não o constitua e não seja constituído por ele.

Nessa compreensão, o urbano configura uma zona privada, na medida em que é específico para algumas categorias sociais, categorias essas semelhantes ao que Arendt (1989) analisou nas organizações greco-romanas, pois são proprietárias de sua força de trabalho ou de um espaço doméstico. Aqueles grupos que não se filiavam ao trabalho celetista, já que apenas o faziam quando da necessidade de aumento da produção industrial, tampouco eram proprietários de sua força de trabalho e de um espaço doméstico e não se tornavam o público dessa zona privada que era o urbano. O público do urbano diz respeito ao trabalhador/ família da nação.

A população operário/família trabalha para o desenvolvimento da nação. $O$ estranho que escapa a essas categorias não figura no público nem no privado/doméstico, não se localiza nos estamentos da nação. Ou seja, a pobreza não aparece como uma objetivação das políticas de Estado, como foco de políticas sociais; a pobreza é o que apenas tem visibilidade nos seus breves encontros com o poder - ocorrências policiais e contaminação do urbano.

A saúde não se refere aos cuidados de si como possibilidade de uma vida política, como descreve Foucault (1985), de uma participação na vida da polis; a saúde, ao ser objetivada como assistência/previdência, é a via pela qual o trabalhador/familia torna-se um objeto público, um sujeito público em termos de estratégias biopolíticas para o desenvolvimento da nação. O que escapa ao público industrial não é dever do Estado como assistência/previdência; o que escapa figura como dejeto, portanto, prejudicial à saúde da população trabalhador/família, prejudicial à identidade nacional e ao desenvolvimento econômico.

É preciso amarrar o sujeito público a um espaço privado, a uma propriedade - a família e o corpo. É preciso inscrever, para existir um sujeito público, a necessidade de operar com o sujeito indivíduo ${ }^{3}$. Desse modo, o que está em jogo no dispositivo não é um sujeito político, mas um sujeito indivíduo, que se formula a partir de um conjunto estratégico que atinge "eficácia na ordem do poder e produtividade na ordem do saber": identidade nacional; desenvolvimento dos meios de produção; sociedade de deveres; medicalização dos corpos. O sujeito-indivíduo diz respeito tanto a uma racionalidade, ou seja, constitui-se por um conjunto de verdades que articulam certa forma de subjetivação, quanto às formas de governamentalidade que investem nessa figura existencial, tornando-a foco de estratégias políticas.

A racionalidade, seja ela do Estado ou do trabalhador/família, engendra-se na objetivação do dever como tarefa, não como direito. Essa racionalidade opera com a individualização da população, individualização que tem como tecnologia a autonomia: "a ênfase é dada à atenção individual, assistencialista e especializada, em detrimento das medidas de saúde pública, de caráter preventivo e de interesse coletivo" (Brasil, 2001, p. 291).

\footnotetext{
3 A distinção que passa a ser feita entre sujeito-político e sujeito-público/indivíduo diz respeito à necessidade de marcar que o sujeito-político se refere à potência política, à potência de vida especificamente, pois o sujeito público/indivíduo também se refere a um corpo político, na medida em que é foco de investimentos do poder sobre a vida. Aqui se quer explicitar que existem configurações distintas de sujeito político, e neste momento a terminologia foi utilizada para enfatizar essa distinção.
} 
SUJEITO PÚBLICO: Indivíduo trabalhador/família

O público industrial cola-se à figura do indivíduo, aliás, torna-se possível justamente pela relação que se estabelece entre público trabalhador/família - indivíduo. Assim, o sujeito público é o indivíduo, e não o cidadão. A analítica dessa relação reside justamente nas tecnologias biopolíticas que capturam o trabalhador como "questão social", como formas de resistência, e o individualizam em termos de compromisso com o desenvolvimento da nação, indivíduo, identidade nacional, bem como em termos de seguridade individual e especializada. A operação que se produz para essa torção do sujeito público, que começa a cidadanizar-se em termos de direitos (entre outros, o movimento operário) e torna-se o sujeito público indivíduo, diz respeito, no campo da saúde pública, aos procedimentos do dispositivo de publicização que definem, segundo Mendes (1999): o Estado como financiador do sistema por meio da Previdência Social; a assistência médica privada como maior prestadora de serviços; o setor privado internacional como o mais significativo produtor de insumos, em especial, de equipamentos médicos e medicamentos.

Esses procedimentos são reforçados pelo fortalecimento do Estado como regulador e centralizador das políticas públicas em saúde; pelo afastamento do trabalhador do controle da Previdência Social na medida em que se desfazem os IAPs, que tinham a participação organizada dos trabalhadores, e se institui o Instituto Nacional de Assistência Médica da Previdência Social (INAMPS); e pela aproximação cada vez maior entre Estado e tecnologia científica, principalmente a ciência médica.

Esses procedimentos engendram certa conformação do público, em que na sua articulação com a saúde, formula o sujeito assistido pelo Estado, e não o sujeito de direito. A saúde pública não engendra corpos políticos, pois se torna uma estratégia política para agenciar um sujeito indivíduo. $\mathrm{O}$ dispositivo de publicização faz justamente a operação de tornar-se condição para a colonização do público/político pelo privado/assistencial. Essa metamorfose do público que o torna objeto do privado circunscreve um território em que público é atributo do Estado e foco da medicina assistencial como estratégia de desenvolvimento econômico privado. "A medicina será um lenitivo para a extrema carência da população. O remédio, uma alternativa para a fome" (Luz, 1986, p. 19).

Essa análise de estratégias políticas, a partir dos procedimentos formulados pela relação entre Estado e medicina privada/assistencial, não defini especificamente um conhecimento que se formou sobre o público, mas as relações de poder que certa forma de inteligibilidade do indivíduo/privado não cessa de exercer sobre o público. Desse modo, a saúde pública passa a constituir um fenômeno para o Estado e para a Medicina em termos de crescimento da nação, um desafio e uma condição para o desenvolvimento da industrialização. Ou seja, a formação de um conceito é em si mesma a formulação histórica de um campo existencial, de um território mediante o qual se estabelecem formas de subjetivação (Foucault, 1995b). Assim, ao falar-se do público colonizado pelo indivíduo/ privado, aponta-se para o nível do vivido, da vida cotidiana como uma série de comportamentos, investimentos, relações que encontram no socialassistencial do Estado e na assistência médica privada suas justificativas e possibilidades.

A vida cotidiana é tomada pela saúde social-assistencial privada na medida em que se estabelece a parceria do Estado como financiador do sistema de saúde e a assistência médica privada como prestadora de serviços e produtora de insumos. Essa colonização da vida cotidiana pelo social-assistencial encontra fundamentos, inclusive, naquilo que seria uma forma de colocála em análise, de produzir outros modos de objetivação: a proposta de cuidados primários acordada na Alma-Ata (Mendes, 1999).

A necessidade de cuidados primários é forjada, no Brasil, como a possibilidade de expansão $\mathrm{da}$ assistência médica àqueles contingentes populacionais que não tinham acesso à saúde, àqueles grupos que margeavam os centros urbanos, mas que eram efeitos da urbanização - periferia e zona rural. A proposta da Alma-Ata seria a elaboração de uma modalidade de assistência de baixo custo com uma abrangência maior. Essa racionalidade é capturada pela biopolítica racista e de desenvolvimento econômico que estabelece para esses grupos, que passam a ter visibilidade no campo da saúde, uma "oferta de tecnologias mais simples e baratas, providas por pessoal de baixa 
qualificação profissional, sem possibilidades de referência a níveis de maior complexidade tecnológica, incluindo a retórica de participação comunitária” (Mendes, 1999, p. 26).

A publicização de um contingente maior da população torna-se correlata da baixa qualidade dos serviços de atenção à saúde. A vida cotidiana da população que não é trabalhador/família ou que, se é, está afastada dos centros urbanos é tomada pelas tecnologias de governo como um objeto "simples e barato", de baixo custo, pois a lógica não é propriamente fazer viver, mas deixar morrer.

Trata-se de um processo de estatização do biológico, segundo Foucault (2005), que coloca a vida no campo político, mas não como uma instância política. A biopolítica não investe na relação entre saúde e possibilidades para a vida política como na experiência greco-romana. Investe, sim, na relação entre o Estado e a vida para regulá-la em termos políticos. A regulação biopolítica tem como conseqüências, na experiência do público, o consumo individual, barato, pouco qualificado do suporte estatal, e não a promoção de um exercício de politização coletiva. É justamente para não haver sujeito político que se investe no sujeito público/indivíduo - é deixar o sujeito político morrer e fazer viver o sujeito público/indivíduo (Santana, 2002).

O Estado, no que tange à saúde pública, investe na especialização e atenção médica sobre o corpo do indivíduo, sobre uma dimensão interna com baixo custo, fragmentando o tecido social entre aqueles que precisam da tutela do Estado e aqueles que se desenvolvem economicamente como prestadores de serviços de tutela ao Estado. Essa biopolítica, ao conformar-se como uma política racista/higienista desenvolvimentista do Estado, formula um jogo que binariza o tecido social: de um lado, o dever de assistência tutelar ao trabalhador/ família e outros/estranhos; de outro, o dever para com o desenvolvimento econômico dos servidores da tutela - medicina privada e industrialização.

\section{PREÂMBULO DE CONSIDERAÇÕES SOBRE O PÚBLICO E O COLETIVO}

O processo de desfiliação produzido pela industrialização capitalista agrava o problema do direito de acesso aos suportes sociais. O público deixa de ser um espaço de trocas, reconhecimento, pertencimento e passa a ser um dispositivo de regulação da população vulnerável, com estratégias biopolíticas.

Essas estratégias biopolíticas criam um território em que as relações são mediadas pelo capital e equalizadas a este. A vida torna-se um foco de intervenção política e o capital um suporte de filiação social, ou seja, para ter acesso aos suportes sociais é necessário o acesso aos meios de produção: "O que se vê então é uma expropriação das redes de vida da maioria da população pelo capital, por meio de mecanismos cuja inventividade e perversão parecem ilimitadas" (Pelbart, 2003, p. 1). A população de desfiliados torna-se uma classe perigosa, ameaçadora de fronteiras, estrangeira às redes comerciais. As formas de biopoder vêm a apresentar-se como uma maneira de o Estado responder a tal situação, não propriamente pela reestruturação dos princípios liberais, mas por uma necessidade de organização do espaço urbano. As formas de biopoder no campo da saúde aparecem por meio da Medicina Social, do Assistencialismo, da Seguridade para o trabalhador/família.

A partir da década de setenta, nessa configuração do público, começa a produzir-se um correlato, uma outra forma de objetivação da saúde. O refugo dessa racionalidade da publicização, que é uma das condições de existência desse dispositivo, começa a apresentar-se de um outro modo. Um acontecimento começa a engendrar uma descontinuidade no dispositivo, apresentando-lhe contradições. Essa descontinuidade histórica não é um grande acontecimento no público, mas um emaranhado de descontinuidades que começam a ter visibilidade no próprio dispositivo. Trata-se da emergência do coletivo como correlato da saúde. O coletivo é produzido por um conjunto de práticas - movimentos sociais e acadêmicos - com pouca visibilidade, visto o cenário de ditadura militar, inicialmente, mas que permite aparecer um outro domínio de objetos e subjetividades no campo da saúde. A coexistência, agora, será entre o público e o coletivo no campo da saúde.

\section{REFERÊNCIAS}

Arendt, H. (1989). A condição humana. Rio de Janeiro: Forense. 
Bauman, Z. (2005). Vidas desperdiçadas. Rio de Janeiro: Jorge Zahar.

BrasiL, Ministério da Saúde (2001). Gestão municipal de saúde: Textos básicos. Rio de Janeiro: Brasil. Ministério da Saúde.

CasteL, R. (1998). As metamorfoses da questão social: Uma crônica do salário. Petrópolis, RJ: Vozes.

Foucault, M. (1974). A verdade e as formas jurídicas. Rio de Janeiro, Cadernos da PUC, 6, 33.

Foucault, M. (1985). História da sexualidade III: O cuidado de si. Rio de Janeiro: Graal.

Foucault, M. (1995a). Microfísica do Poder. Rio de Janeiro: Graal.

Foucault, M. (1995b). O sujeito e o poder. In: H. Dreyfus, \& P., Rabinow. Michel Foucault, uma trajetória filosófica: Para além do estruturalismo e da hermenêutica. Rio de Janeiro: Forense.

Foucault, M. (1999). História da sexualidade I: A vontade de saber. Rio de Janeiro: Graal.

Foucault, M. (2003). A governamentalidade: Ditos e escritos IV. Rio de Janeiro: Forense Universitária.

Foucault, M. (2005). Em defesa da sociedade. São Paulo: Martins Fontes.

Luz, M. T. (1986). As instituições médicas no Brasil: Instituição e estratégia de hegemonia. Rio de Janeiro: Graal.
Mendes, E. V. (1999). Distrito sanitário: O processo social de mudança das práticas sanitárias do Sistema Único de Saúde. Rio de Janeiro: HUCITEC.

Pal Pelbart, P. (2003). Vida capital: Ensaios de biopolítica. São Paulo: Iluminuras.

Pinto, C. (1999). Foucault e as Constituições brasileiras: quando a lepra e a peste se encontram com os nossos excluídos. Educação \& Realidade, 24(2), 33-56.

Portal da Saúde (2005). Recuperado em 3 ago. 2007. do Portal da Saúde: http:/ / portal.saude.gov.br/ saude/legislação

Santana, D. (2002). Corpos de passagem: Ensaios sobre a subjetividade contemporânea. São Paulo: Estação Liberdade.

Serres, J. (2003). É preciso cuidar da lepra: políticas sanitárias no Rio Grande do Sul nas primeiras décadas da República. Boletim de Saúde, 17(1), 84-97.

Recebido: 14/02/2008

Received: 02/14/2008

Aprovado: 03/03/2008

Approved: 03/03/2008 